\title{
Various types of intracorporeal esophagojejunostomy after laparoscopic total gastrectomy for gastric cancer
}

\author{
Jung Ho Shim $\cdot$ Han Mo Yoo $\cdot$ Seong II Oh • \\ Myung Jin Nam · Hae Myung Jeon · \\ Cho Hyun Park $\cdot$ Kyo Young Song
}

Received: 16 July 2012 / Accepted: 9 October 2012/Published online: 25 October 2012

(C) The International Gastric Cancer Association and The Japanese Gastric Cancer Association 2012

\begin{abstract}
Background Even for expert surgeons, esophagojejunostomy after laparoscopic total gastrectomy (LTG) is not always easy to perform. Herein, we compare various types of esophagojejunostomy in terms of the technical aspects and postoperative outcomes.

Methods A total of 48 patients underwent LTG for gastric cancer by the same surgeon. Four types of intracorporeal esophagojejunostomies have been applied after LTG: type A, a conventional anvil head method; type B, an OrVil $^{\mathrm{TM}}$ system method; type C, a hemi-double stapling technique with anvil head; and type $\mathrm{D}$, side-to-side esophagojejunostomy with linear stapler. We describe and review these types of esophagojejunostomy using a step-by-step approach.

Results The mean reconstruction times were longer for types A and B than for types C and D $(p<0.05)$. In terms of complications, there were five cases $(10.4 \%)$ of anastomosis leakage, which was more common in types $\mathrm{A}$ and B: two cases in each of type A and B and one case in type C. Moreover, anastomosis stricture requiring intervention was more common in types $\mathrm{A}$ and $\mathrm{B}(p<0.05)$.

Conclusions To date, there are no reliable reconstruction methods after LTG. Therefore, special care is needed to prevent postoperative complication regardless of methods; also, technical innovations to support development of the safest methods of esophagojejunostomy are warranted.
\end{abstract}

J. H. Shim - H. M. Yoo - S. I. Oh · M. J. Nam •

H. M. Jeon - C. H. Park - K. Y. Song ( $\square)$

Division of Gastrointestinal Surgery, Department of Surgery, Minimal Access and Robotic Surgery Center, Seoul St. Mary's Hospital, College of Medicine, The Catholic University of Korea, 505 Banpo-dong, Seocho-gu, Seoul 137-701, Korea e-mail: skygs@catholic.ac.kr; skys9615@gmail.com
Keywords Laparoscopic total gastrectomy . Intracorporeal esophagojejunostomy $\cdot$ Reconstruction methods · Outcomes

\section{Introduction}

Laparoscopic distal gastrectomy (LDG) has been widely used for treating patients with gastric cancer since Kitano et al. [1] published their report in 1994. LDG has been accepted as an alternative procedure in Korea and Japan [2, 3] because it has been proven to be associated with less postoperative pain, an earlier return of normal bowel function, shorter hospitalization periods, and equivalence to open surgery with regard to oncological aspects [4]. In contrast, laparoscopic total gastrectomy (LTG) for gastric cancer has only been performed at a limited number of hospitals. According to the nationwide survey of Korea in 2009 [5], the number of surgeons using a laparoscopic approach for gastric cancer operations has surprisingly increased. However, the frequency of using LTG has remained constant. Moreover, only a few studies have analyzed the surgical outcomes of LTG [6-9]. The reluctance to perform LTG originates from the technical difficulty of reconstruction and the fear of complications such as anastomotic leakage or stricture. One study reported that the rates of postoperative stricture at the esophagojejunostomy site were $9 \%$ and $1 \%$ in laparoscopic and open total gastrectomy, respectively [10]. Although various types of esophagojejunal anastomosis are described in the literature, there is no widely accepted standard technique in LTG.

Therefore, we report herein our experiences with the various types of anastomosis after LTG and also an evaluation of the postoperative surgical outcomes according to the type of anastomosis. 


\section{Methods}

\section{Patients}

A total of 48 patients with gastric cancer underwent LTG in our hospital from March 2009 to July 2011. All the operations were performed by a single surgeon (S.K.-Y.). From the prospectively collected gastric cancer registry, the following clinical data from the patients were collated: age, sex, body mass index (BMI), type of anastomosis, time required for anastomosis, extent of lymph node dissection, operation time, length of postoperative hospital stays, and early and late postoperative complications. Postoperative complications were classified according to the ClavienDindo classification of surgical complications [11], and grades of complications were recorded. Approval from our institutional review board was obtained.

Surgical techniques

\section{General surgical procedures}

The patients were placed under general anesthesia in the supine position with legs spread. A total of five ports were used. The first port was inserted at the umbilicus for the laparoscope. Two ports were placed on the right side for the operating surgeon, and two ports were placed on the left side for the first assistant. The liver was retracted upward using previously described methods [12]. Extragastric lymph node dissection (D1 + beta or D2) was performed as described in the Japanese classification of gastric carcinoma [13]. After the dissection of lymph nodes along the greater and lesser curvatures of the stomach, the duodenum was divided using the Endo GIA stapler (Covidien, Mansfield, MA, USA), at which point the stomach was ready for total gastrectomy, which was achieved via a series of steps. In the first step, the vagus nerve was carefully exposed and divided to avoid injuring the muscle layer of the esophagus, and then the right-hand wall of the esophagus was prepared for esophagojejunostomy. For reconstruction after LTG, we used four types of methods according to our protocol. We used type A or B for tumors located near the Z-line, such as Siewert type III gastric cancer. We used type $\mathrm{C}$ or $\mathrm{D}$ for tumors located at the cardia or within at least $2-3 \mathrm{~cm}$ below the Z-line, in which cases we could guarantee that the stapled line did not enclose the tumor. Type $\mathrm{C}$ has been introduced since late 2009 , although other types began to be used at a similar time.

\section{Specific technical details of various esophagojejunostomy} types

Type A: esophagojejunostomy with conventional anvil head The esophagus is transected $2 \mathrm{~cm}$ above the esophagogastric junction using an Endo GIA ${ }^{\mathrm{TM}}$ stapler. Before opening the esophageal stump, laparoscopic intestinal clamping is applied to the abdominal esophagus to prevent it from pulling up (Fig. 1a, b). With an anvil holder, the operating surgeon then inserts an anvil head into the esophageal stump, and an intracorporeal purse-string suture is applied in preparation for esophagojejunostomy (Fig. 1c). Finally, a $25-\mathrm{mm} \mathrm{EEA}^{\mathrm{TM}}$ stapler (Covidien) is introduced through the Roux limb, enabling esophagojejunostomy by firing the stapler (Fig. 1d).

Type B: esophagojejunostomy with OrVil ${ }^{T M}$ (Covidien) The OrVil ${ }^{\mathrm{TM}}$ system is a ready-to-use anvil delivery device that is designed to transorally insert the anvil into the abdominal esophagus, similar to inserting the orogastric tube through the mouth. In the OrVil ${ }^{\mathrm{TM}}$ system, the orogastric tube is connected to the center rod of the anvil so that the anvil can be transorally delivered into the esophagus. The orogastric tube is easily removed by cutting the connecting thread. After full mobilization of the abdominal esophagus, the esophagus is transected $2 \mathrm{~cm}$ above the esophagogastric junction with an Endo GIA ${ }^{\mathrm{TM}}$ stapler. The $\mathrm{OrVil}^{\mathrm{TM}}$ tube is then transorally introduced into the esophagus. When the operator identifies that the $\mathrm{OrVil}^{\mathrm{TM}}$ tube has reached the esophageal stump, a small hole is created at the lateral edge of the esophageal stump. The tube is then extracted through the hole until the anvil reaches the esophageal stump (Fig. 2a), at which time the tube is disconnected from the anvil by cutting the connecting thread and removed from the abdominal cavity (Fig. 2b, c). The EEA ${ }^{\mathrm{TM}}$ stapler is then introduced through the Roux limb, enabling esophagojejunostomy by firing the stapler (Fig. 2d).

Type C: hemi-double stapling technique with anvil head Before reconstruction, the anvil head of a circular stapling device is prepared with a 2-0 silk or vicryl suture that is bound at the hole of the tip. The anvil is brought into the peritoneal cavity. The operating surgeon then makes a hole to introduce the anvil head into the esophagus with a harmonic scalpel (Fig. 3a). The anvil with the suture is inserted into the esophagus through the esophagotomy, and the anvil head is extracted through the hole by the assisting surgeon by holding the thread upward. The esophageal stump is prepared for esophagojejunostomy by applying an Endo GIA $^{\mathrm{TM}}$ stapler (Fig. 3b). After making the esophageal stump, the center rod of the anvil head is removed (Fig. 3c). The $\mathrm{EEA}^{\mathrm{TM}}$ stapler is then introduced through the Roux limb, enabling esophagojejunostomy by firing the stapler (Fig. 3d).

Type D: side-to-side esophagojejunostomy First, esophagotomy is performed with a harmonic scalpel to insert an 

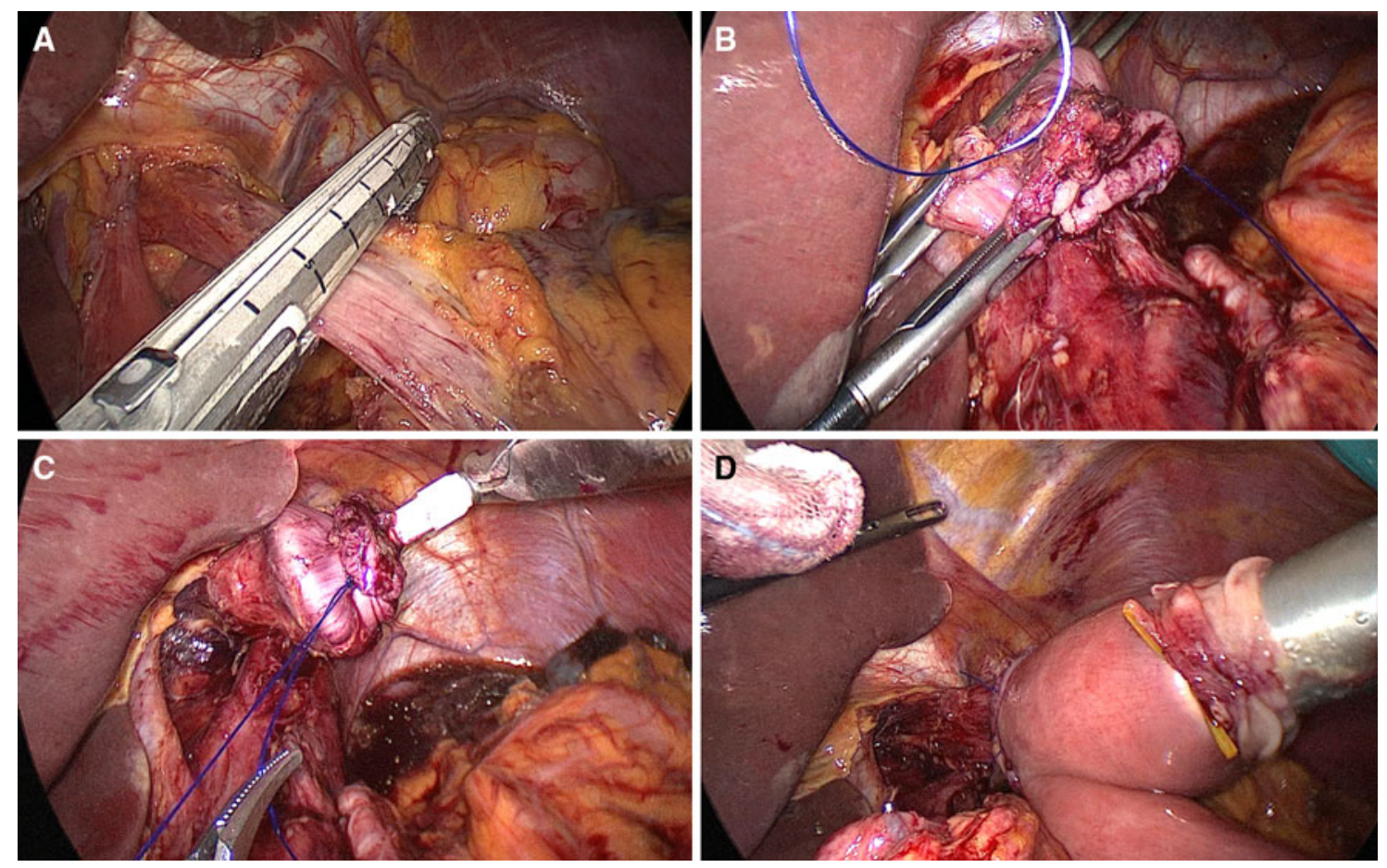

Fig. 1 Type A: esophagojejunostomy with conventional anvil head. The esophagus is transected $2 \mathrm{~cm}$ above the esophagogastric junction using an Endo GIA ${ }^{\mathrm{TM}}$ stapler. Before transecting the esophagus, laparoscopic intestinal clamping is applied to the abdominal

esophagus (a, b). An anvil head is inserted into the esophageal stump, and intracorporeal purse-string suture is applied (c). An EEA $^{\mathrm{TM}}$ stapler is introduced through the Roux limb, and end-to-side esophagojejunostomy is completed (d)
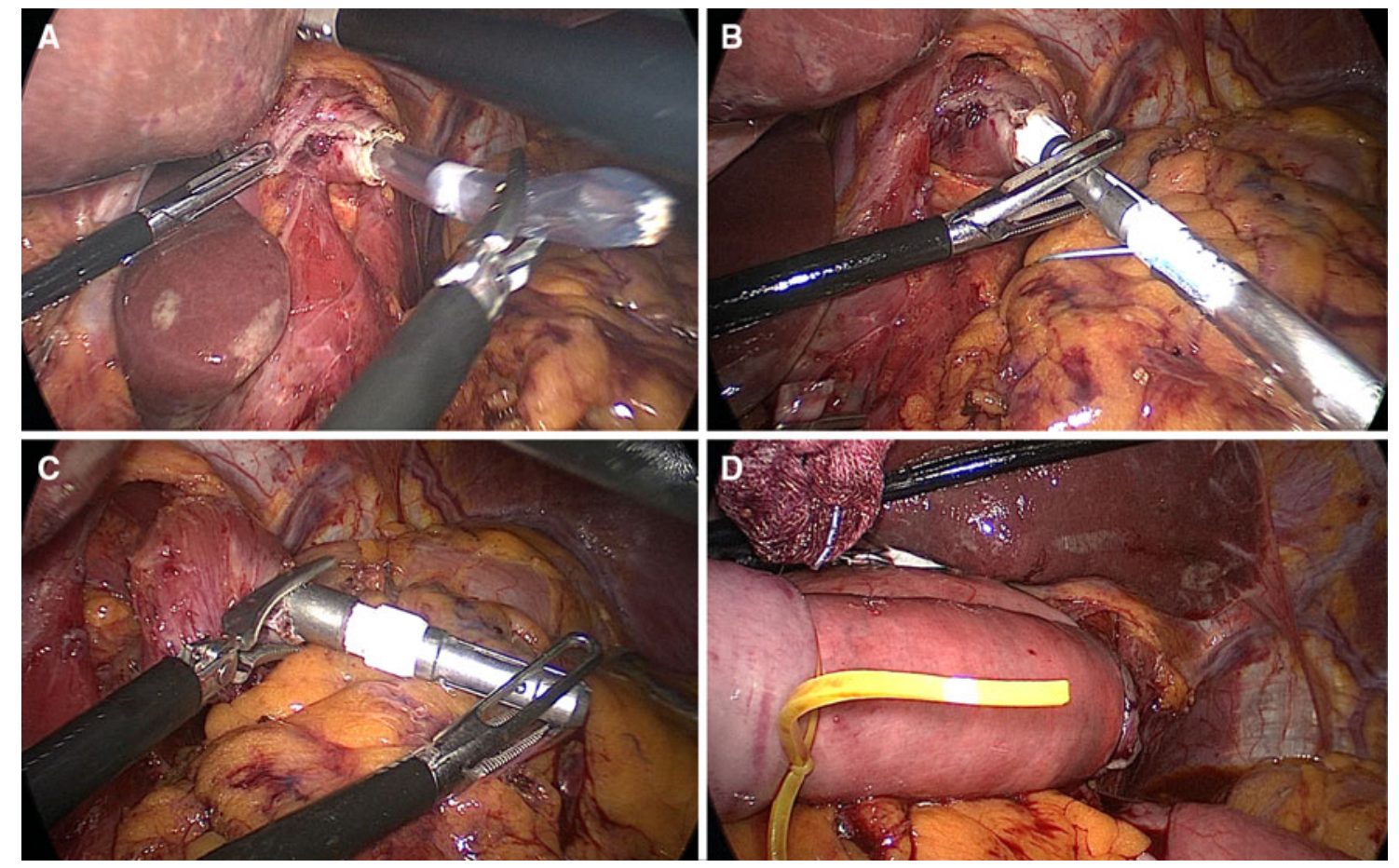

Fig. 2 Type B: esophagojejunostomy with $\mathrm{OrVil}^{\mathrm{TM}}$. The OrVil ${ }^{\mathrm{TM}}$ is advanced through the hole until the anvil reaches the esophageal stump (a), and then the tube is disconnected from the anvil by cutting the connecting thread and removed from the abdominal cavity $(\mathbf{b}, \mathbf{c})$.

After the anvil is introduced into the abdominal esophagus, it can facilitate esophagojejunostomy and untilt the pretilted head automatically. An esophagojejunostomy is achieved by firing the EEA ${ }^{\mathrm{TM}}$ stapler $(\mathbf{d})$ 

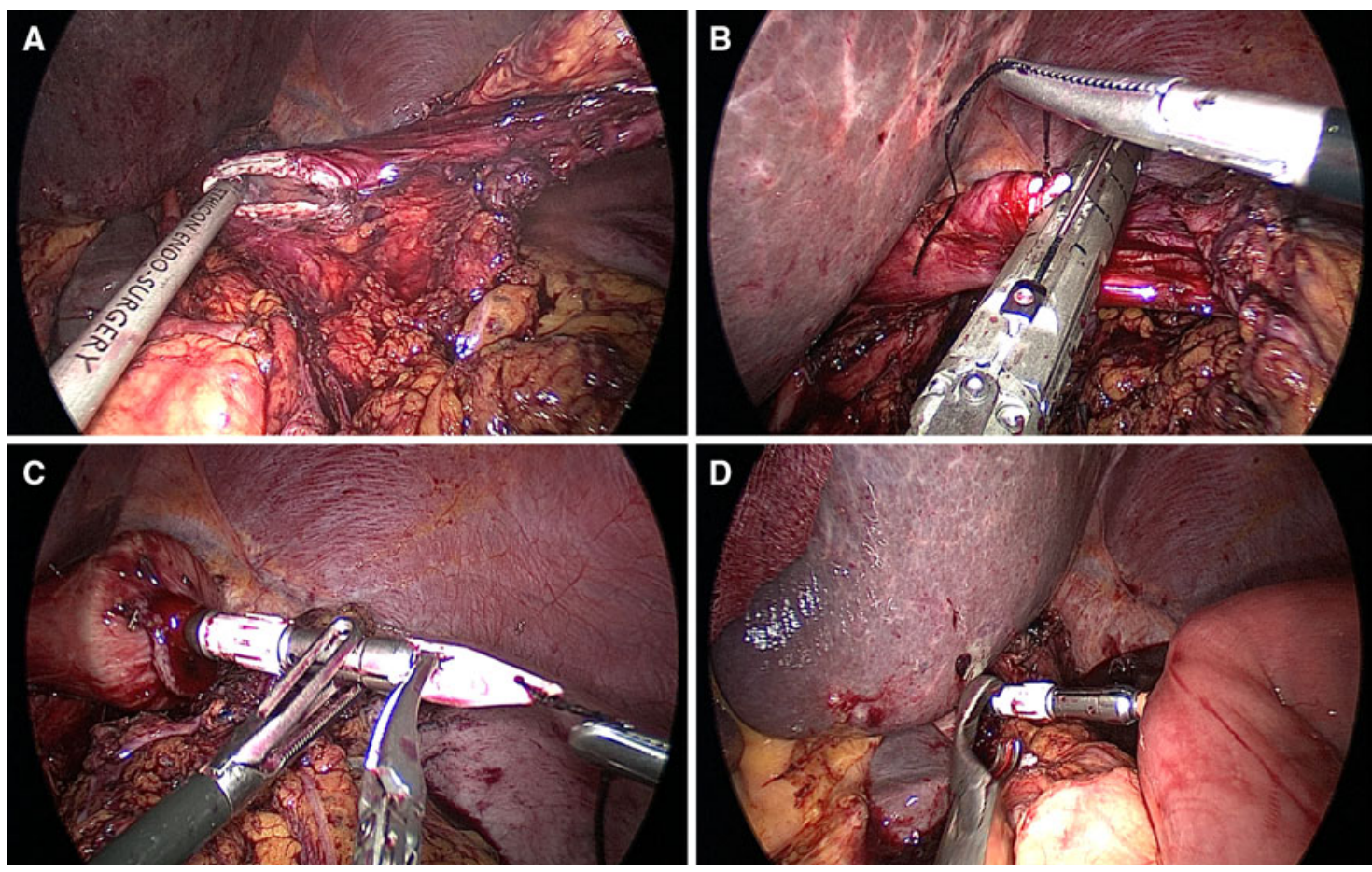

Fig. 3 Type C: hemi-double stapling technique with anvil head. After making a small hole at the anterior wall of the stomach (a), the anvil head, which is connected to the thread, is inserted. The esophagus is cut just below the site of the anvil by applying the Endo

Endo GIA ${ }^{\mathrm{TM}}$ fork (Fig. 4a). To make a Roux limb, the jejunum is transected from 20 to $30 \mathrm{~cm}$ below the Treitz's ligament using an Endo GIA ${ }^{\mathrm{TM}}$ stapler. A small enterotomy is then made to enable insertion of an Endo GIA ${ }^{\mathrm{TM}}$ fork at the antimesenteric side of the jejunum. After one fork of the Endo GIA ${ }^{\mathrm{TM}}$ stapler is inserted into the opening in the jejunal limb toward the cranial side of the lumen, the jejunal limb is drawn up and another fork of the Endo GIA ${ }^{\mathrm{TM}}$ stapler is inserted into the esophagus. After firing the Endo GIA $^{\mathrm{TM}}$ stapler, the esophagojejunostomy is facilitated in a side-to-side fashion (Fig. 4b). Additional firing of a linear stapler converts the two openings into a single lumen, and the hole is closed by intracorporeal continuous suture (Fig. 4c, d).

\section{Statistical analysis}

All data are expressed as mean \pm standard deviation (SD). The parameters related to operative outcomes and complications between the groups were analyzed using the Student's $t$ test, and $p<0.05$ was considered significant. Statistical analyses were performed using SPSS version 13.0 (SPSS, Chicago, IL, USA).

$\mathrm{GIA}^{\mathrm{TM}}$ stapler (b). After making the esophageal stump, the center rod of the anvil head is removed (c). An end-to-side esophagojejunostomy is completed, and the jejunal end is closed with an Endo GIA ${ }^{\mathrm{TM}}$ stapler (d)

\section{Results}

Patient characteristics and operation data

The patients included in the study comprised 33 men and 15 women, with a mean age of 56.7 years. Their mean BMI was $24.3 \mathrm{~kg} / \mathrm{m}^{2}$. Twelve patients had co-morbidities: 2 had coronary artery disease, 7 had hypertension, 1 had mitral valve disease, 1 had kidney insufficiency, and 1 had diabetes mellitus. Most (75\%) of the tumors were staged as early gastric cancer.

Age, BMI, and sex did not differ significantly between the groups. Moreover, there were no significant differences in the pathological stage, extent of lymph node dissection, or total number of retrieved lymph nodes among the four types of anastomosis. The mean operation times did differ significantly, with type A taking the longest time, followed in descending order by types $\mathrm{B}, \mathrm{C}$, and $\mathrm{D}(\mathrm{A}, 229.1 \pm 45.7 \mathrm{~min}$; B, $226.5 \pm 51.4 \mathrm{~min} ; \mathrm{C}, 209.0 \pm 39.4 \mathrm{~min} ; \mathrm{D}, 205.5 \pm 33.1$ $\min ; p=0.037)$. The mean reconstruction times also differed significantly, with type A taking the longest, again followed by types $\mathrm{B}, \mathrm{C}$, then $\mathrm{D}$ in that order (A, $43.2 \pm 11.5 \mathrm{~min}$; $\mathrm{B}$, $42.8 \pm 11.3 \mathrm{~min} ; \mathrm{C}, 37.0 \pm 7.1 \mathrm{~min} ; \mathrm{D}, 34.3 \pm 6.4 \mathrm{~min} ;$ $p=0.041$ ). The mean postoperative hospital stay was 

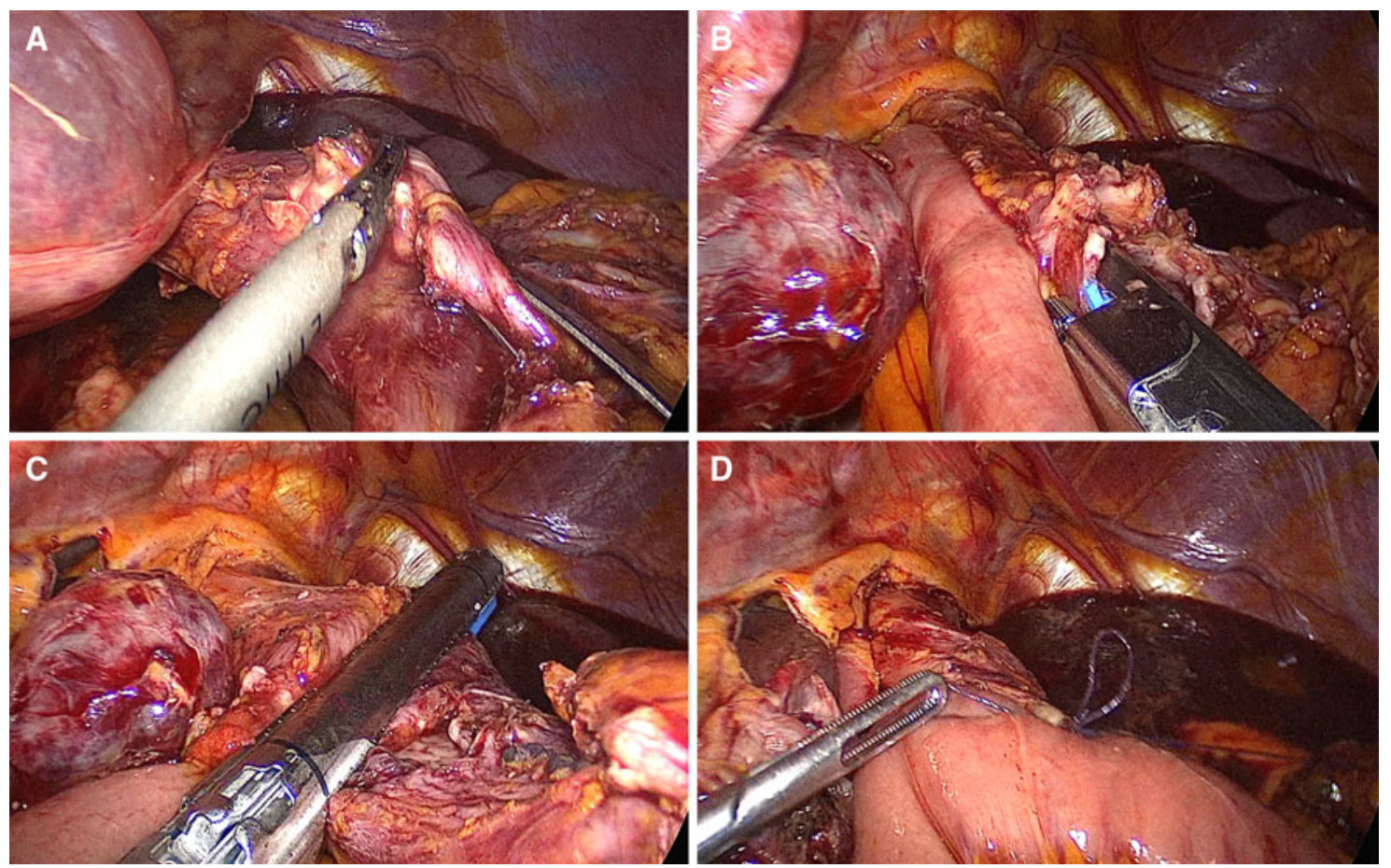

Fig. 4 Type D: side-to-side esophagojejunostomy. First, esophagotomy is performed with a harmonic scalpel to insert an Endo GIA ${ }^{\mathrm{TM}}$ stapler fork (a). A Roux limb is drawn up, and another fork of the stapler is inserted into the esophagus. After firing the Endo GIA ${ }^{\mathrm{TM}}$

10.3 days for type $\mathrm{A}, 8.4$ days for type $\mathrm{B}, 9.3$ days for type $\mathrm{C}$, and 8.8 days for type $\mathrm{D}(p=0.049)$.

Postoperative complications

Table 1 summarized the details of postoperative complications among the groups. Esophagojejunostomy site leakage was observed in 5 patients: 2 in type A, 2 in type $\mathrm{B}$, and 1 in type C. Duodenal stump leakage occurred in 2 patients: 1 in type A and 1 in type C. Anastomosis site stricture was experienced by 11 patients: 5 in type A, 4 in type $\mathrm{B}, 1$ in type $\mathrm{C}$, and 1 in type D. Of these patients, 5 underwent balloon dilatation.

\section{Discussion}

Performing esophagojejunostomy is considered a main obstacle in LTG [10]. During laparoscopy-assisted total gastrectomy, most surgeons previously performed extracorporeal esophagojejunostomy using additional minilaparotomy. However, it is not always feasible through the deep, narrow abdominal space. This procedure can be adversely affected if the patient is obese and entails a risk of unnecessary tension at the anastomosis. Therefore, we have performed LTG with intracorporeal esophagojejunostomy and have investigated four types of anastomosis

stapler, the esophagojejunostomy is facilitated in a side-to-side fashion (b). Additional firing of the Endo GIA ${ }^{\mathrm{TM}}$ stapler converts the two openings into a single lumen, and the hole is closed by intracorporeal continuous suture $(\mathbf{c}, \mathbf{d})$

since 2009. We summarize here the surgical outcomes of previous studies for the various types of esophagojejunostomies in LTG (Table 2).

A commercially available device, the OrVil, consisting of a $25-\mathrm{mm}$ anvil with the head pretilted and the tip attached to an 18-Fr. orogastric tube, permits esophagojejunal stapled anastomosis, with the anvil introduced through the mouth. This system appears to lessen the burden of retrograde insertion of the anvil head, which can tear the esophagus, but as previously noted, it entails the risks of oral bacterium contamination and injury to the esophagus during insertion [14].

Jeong and Park [14] summarized their surgical outcomes of LTG with type B esophagojejunostomy. They reported a mean operation time of $194 \mathrm{~min}$ (range, 160-270 $\mathrm{min}$ ), and one patient had an intraabdominal abscess that required surgical drainage. In our study, the mean operation time was $226 \mathrm{~min}$ (range, 145-260 min), and no patient had surgical intervention.

As a result of these drawbacks of the OrVil system, we also investigated the use of a the conventional EEA stapling device to facilitate esophagojejunostomy. To facilitate the "purse-string" procedure, several modifications have been proposed. However, in total laparoscopic procedures, none of these seemed easy. The insertion of the anvil head to the distal esophagus is the most technically challenging and stressful step. 
Table 1 Postoperative complications according to the different types of esophagojejunostomy

\begin{tabular}{|c|c|c|c|c|c|}
\hline & Type A $(n=12)$ & Type B $(n=12)$ & Type C $(n=14)$ & Type $\mathrm{D}(n=10)$ & $p$ value \\
\hline EJstomy site leakage (CD) & 2 (IIIa) & 2 (IIIa) & 1 (IIIa) & 0 & 0.044 \\
\hline EJstomy site stenosis & 5 & 4 & 1 & 1 & 0.050 \\
\hline Balloon dilatation & 3 & 2 & 0 & 0 & 0.037 \\
\hline Duodenal stump leakage & 1 (IIIa) & 0 & 1 (IIIa) & 0 & 0.284 \\
\hline Ileus & 1 (I) & $2(\mathrm{I})$ & $1(\mathrm{I})$ & 0 & 0.145 \\
\hline Pneumonia & 0 & 1 (II) & 0 & 1 (II) & 0.289 \\
\hline Pleural effusion & $2(\mathrm{I})$ & 2 (I) & 1 (IIIa) & $1(\mathrm{I})$ & 0.156 \\
\hline Postoperative bleeding & 0 & 0 & 1 (IIIb) & 0 & 0.209 \\
\hline
\end{tabular}

Type A, conventional esophagojejunostomy with EEA and anvil; type B, esophagojejunostomy with the OrVil system; type C, hemi-double stapling technique: insertion of the anvil head through gastrotomy before cutting the esophagus and making an esophageal stump with the EndoGIA stapler. Type D, side-to-side esophagojejunostomy with the Endo GIA stapler

EJstomy esophagojejunostomy, $C D$ Clavien-Dindo classification

Table 2 Literature review of reconstruction methods after laparoscopic total gastrectomy

\begin{tabular}{|c|c|c|c|c|c|c|}
\hline Reference & Title of reconstruction & Type & $N$ & $\begin{array}{l}\text { Operation } \\
\text { time (min) }\end{array}$ & $\begin{array}{l}\text { Rate of } \\
\text { complications } \\
(\%)\end{array}$ & Comments \\
\hline Jeong [14] & $\begin{array}{l}\text { Intracorporeal circular } \\
\text { stapling } \\
\text { esophagojejunostomy } \\
\text { using the transorally } \\
\text { inserted anvil }\end{array}$ & $\mathrm{B}$ & 16 & 194 & 6.3 & $\begin{array}{l}\text { Useful in obese patients } \\
\text { and EGJ cancer }\end{array}$ \\
\hline $\begin{array}{l}\text { Takiguchi } \\
\text { [15] }\end{array}$ & $\begin{array}{l}\text { Laparoscopic purse- } \\
\text { string suture }\end{array}$ & A & 10 & NA & 10 & $\begin{array}{l}\text { One minor leakage } \\
\text { Use Endo-stitch and } \\
\text { Endo-loop }\end{array}$ \\
\hline Usui [16] & $\begin{array}{l}\text { Endoscopic purse-string } \\
\text { suture instrument } \\
\text { "Endo-PSI(II)" }\end{array}$ & A & 23 & 306 & 4.3 & $\begin{array}{l}\text { Endo-PSI is suitable } \\
\text { and feasible }\end{array}$ \\
\hline Hiki [17] & $\begin{array}{l}\text { A modified technique to } \\
\text { protect the esophagus }\end{array}$ & $\mathrm{C}$ & 11 & 237 & 18.5 & $\begin{array}{l}\text { Two anastomosis } \\
\text { strictures can be used: } \\
\text { esophagojejunostomy } \\
\text { and } \\
\text { esophagogastrostomy }\end{array}$ \\
\hline Inaba [18] & Overlap method & $\mathrm{D}$ & 53 & 373 & 24.5 & $\begin{array}{l}\text { Two anastomosis } \\
\text { leakage } \\
\text { Safe and feasible }\end{array}$ \\
\hline
\end{tabular}

Takiguchi et al. [15] and Usui et al. [16] reported their outcomes of LTG with type A reconstruction. Takiguchi et al. [15] developed a simple laparoscopic purse-string suture technique using a semiautomatic suturing device (Endo Stitch, Covidien). Usui et al. [16] developed an endoscopic purse-string instrument, the so-called Endo-PSI (Hope Electronics, Chiba, Japan). Their mean operation time was longer than ours: 301 versus $229 \mathrm{~min}$. One minor leakage of esophagojejunostomy happened with no open conversion. Although it seemed applicable, the jaw of the "Endo-PSI" was $50 \mathrm{~mm}$ in size and sometimes it was not always easy to use in a narrow-angled abdominal space.

Takiguchi et al. used Endostitch ${ }^{\circledR}$, an semiautomatic suturing device, which was designed to make purse-string sutures effectively. They used five trocars instead of four, and the additional 33-mm trocar was for the Endostitch ${ }^{\circledR}$. Although the Endostitch was a ready-to-make suture device, it required additional troca and could not be a solution for secure anvil head insertion to the esophagus.

Hiki et al. [17] developed a modified laparoscopic esophagogastric circular stapled anastomosis. By this method, they eliminated the necessity of making pursestring sutures and reduced the difficult of large, stiff anvil insertion. Before making the esophageal stump, only the anterior wall of the stomach was opened for entry of the anvil, and after the introduction of the anvil, the esophagus was transected. In their report, they prepared an anvil head with detachable sutures connected to a retrievable Levin tube, which they used while performing laparoscopic proximal gastrectomy. We modified this method slightly 
and used it to perform esophagojejunostomy. Before making the esophageal stump, gastrotomy was performed on the anterior wall to insert the anvil head. It was an easyto-perform technique; however, it was required to perform it on selective cases in which the tumor located $2-3 \mathrm{~cm}$ below from the esophagojejunal (EJ) junction.

Inaba et al. introduced "overlapped" esophagojejunostomy, performed in a relatively large series of LTG, which comprised 53 cases. This technique was designed to reduce the complexity of anastomosis with a circular stapler [18]. A longer operation time was required compared to ours: a mean operation time of 373 min versus $205 \mathrm{~min}$ each. Also, they reported higher complication rates of $24.5 \%$ including anastomotic leakage and stenosis. It seemed "easy-to-do" under the limited laparoscopic vision and therefore lessens the burden of injury to the esophageal wall as compared with the circular stapler. Moreover, minilaparotomy for esophagojejunostomy is not necessary. However, it is necessary to ensure a sufficient length of the abdominal esophagus for the anastomosis, especially in cases where the tumor is located near the esophagogastric junction.

Although each study described the merits and feasibility of its own method, direct comparison between the types of anastomosis had not done previously. To the best of our knowledge, this is the first report that compares the four types of anastomosis after LTG.

We recommend that the reconstruction type must be selected on the basis of the location of the tumor. For example, for tumors located near the esophagogastric (EG) junction, type A or B would be appropriate, and for the tumors located at least $3 \mathrm{~cm}$ below from the EG junction, type $\mathrm{C}$ or $\mathrm{D}$ would be safe. Also, if the surgeon was not well experienced with the laparoscopic purse-string technique, type $\mathrm{C}$ or $\mathrm{D}$ would be a relatively good choice.

This study has several limitations. First, because it is retrospective, it is presumed to have a critical selection bias and we cannot conclude which type would be superior. Second, four types of reconstruction have been used with various timelines. Therefore, the matter of the learning curve for the technique can be an issue. Although all four types of reconstruction have been performed by a single, laparoscopic expert, there could be a matter of an intrapersonnel learning curve. Third, we also tried to use our own selection criteria for reconstruction types, but there is also the matter of the surgeon's discretion to select the type.

\section{Conclusions}

In conclusion, it is technically feasible to perform LTG. However, it is still problematic to perform a secure esophagojejunostomy laparoscopically.
Even with the technical advances of laparoscopic instruments, there is still controversy with regard to the optimal methods for esophagojejunostomy. Thus, there is currently no method that can ensure maximal safety or feasibility. Therefore, special care is needed to prevent postoperative complication regardless of the method. Also, technical innovations to support development of the safest methods of esophagojejunostomy are warranted.

Acknowledgments Dr. Jung Ho Shim, Dr. Han Mo Yoo, Dr. Seong Il Oh, Dr. Myung Jin Nam, Dr. Hae Myung Jeon, Dr. Cho Hyun Park, and Dr. Kyo Young Song have no conflicts of interest or financial ties to disclose.

\section{References}

1. Kitano S, Iso Y, Moriyama M, Sugimachi K. Laparoscopy assisted Billroth I gastrectomy. Surg Laparosc Endosc. 1994; $4: 146-8$.

2. Song KY, Kim SN, Park CH. Laparoscopy-assisted distal gastrectomy with D2 lymph node dissection for gastric cancer: technical and oncologic aspects. Surg Endosc. 2008;22:655-9.

3. Kodera Y, Fujiwara M, Ohashi N, Nakayama G, Koike M, Morita $\mathrm{S}$, et al. Laparoscopic surgery for gastric cancer: a collective review with meta-analysis of randomized trials. J Am Coll Surg. 2010;211:677-86.

4. Kim HH, Hyung WJ, Cho GS, Kim MC, Han SU, Kim W, et al. Morbidity and mortality of laparoscopic gastrectomy versus open gastrectomy for gastric cancer: an interim report-a phase III multicenter, prospective, randomized trial (KLASS Trial). Ann Surg. 2010;251:417-20.

5. Jeong O, Park YK. Clinicopathological features and surgical treatment of gastric cancer in South Korea: the results of 2009 nationwide survey on surgically treated gastric cancer patients. J Gastric Cancer. 2011;11:69-77.

6. Hanisch E, Ziogas D, Baltogiannis G, Katsios C. Laparoscopic total gastrectomy: further progress in gastric cancer. Surg Endosc. 2010;24:2355-77.

7. Kinoshita T, Shibasaki H, Oshiro T, Ooshiro M, Okazumi S, Katoh R. Comparison of laparoscopy-assisted and total laparoscopic Billroth-I gastrectomy for gastric cancer: a report of shortterm outcomes. Surg Endosc. 2011;25:1395-401.

8. Mochiki E, Toyomasu Y, Ogata K, Andoh H, Ohno T, Aihara R, et al. Laparoscopically assisted total gastrectomy with lymph node dissection for upper and middle gastric cancer. Surg Endosc. 2008;22:1997-2002.

9. Jeong GA, Cho GS, Kim HH, Lee HJ, Ryu SW, Song KY. Laparoscopy-assisted total gastrectomy for gastric cancer: a multicenter retrospective analysis. Surgery (St. Louis). 2009;146:469-74.

10. Lee SE, Ryu KW, Nam BH, Lee JH, Kim YW, Yu JS, et al. Technical feasibility and safety of laparoscopy-assisted total gastrectomy in gastric cancer: a comparative study with laparoscopy-assisted distal gastrectomy. J Surg Oncol. 2009;100: $392-5$.

11. Dindo D, Demartines N, Clavien PA. Classification of surgical complications: a new proposal with evaluation in a cohort of 6336 patients and results of a survey. Ann Surg. 2004;240: 205-13.

12. Lee JH, Ryu KW, Doh YW, Bae JS, Kim YW, Bae JM. Liver lift: a simple suture technique for liver retraction during laparoscopic gastric surgery. J Surg Oncol. 2007;95:83-5. 
13. Nakajima T. Gastric cancer treatment guidelines in Japan. Gastric Cancer. 2002;5:1-5.

14. Jeong O, Park YK. Intracorporeal circular stapling esophagojejunostomy using the transorally inserted anvil (OrVil) after laparoscopic total gastrectomy. Surg Endosc. 2009;23:2624-30.

15. Takiguchi S, Sekimoto M, Fujiwara Y, Miyata H, Yasuda T, Doki Y, et al. A simple technique for performing laparoscopic purse-string suturing during circular stapling anastomosis. Surg Today. 2005;35:896-9.

16. Usui S, Nagai K, Hiranuma S, Takiguchi N, Matsumoto A, Sanada K. Laparoscopy-assisted esophagoenteral anastomosis using endoscopic purse-string suture instrument "Endo-PSI (II)" and circular stapler. Gastric Cancer. 2008;11:233-7.

17. Hiki N, Fukunaga T, Yamaguchi T, Nunobe S, Tokunaga M, Ohyama S, et al. Laparoscopic esophagogastric circular stapled anastomosis: a modified technique to protect the esophagus. Gastric Cancer. 2007;10:181-6.

18. Inaba K, Satoh S, Ishida Y, Taniguchi K, Isogaki J, Kanaya S, et al. Overlap method: novel intracorporeal esophagojejunostomy after laparoscopic total gastrectomy. J Am Coll Surg. 2010;211: e25-9. 